\title{
Productivity Theory for Industrial Engineering
}

\author{
Usubamatov $\mathrm{R}^{*}$ \\ Kyrgyz State Technical University named after I. Razzakov, Kyrgyzstan
}

Submission: September 9, 2017; Published: November 16, 2017

*Corresponding author: Ryspek Usubamatov, Kyrgyz State Technical University named after I. Razzakov, 66Aitmatov Avenue, 720044 Bishkek, Kyrgyzstan, Tel: +996553 722 755; E-mail: ryspek0701@yahoo.coom

\section{Editorial}

In the course of the centuries, manufacturing industries accumulated experience in creating of different machines and systems for production of various goods. Today manufacturing industries are using numerous diversity of machines and systems that expressed in different designs starting from the single productive machines and finishing by complex automated production lines equipped with robots and controlled by computers. Evolution of the production machines and systemspassed long way with mistakes and positive engineering solutions. Which is mostly, result of accumulated experience. The deep analysis of the numerous designs of machines and systems demonstrates that there is reasonable links and regularities that enable performing the design concepts for any types of production systems that can be jobshop or mass and fast changeable manufacturing processes. Contemporary production machines and systems definitely demonstrate the growing complexity in designs of machineries in industrial engineering. The nearest future will manifest machineries that more complex in design than known one. New machines and systems will represent the conglomerate that based on mechanical, electrical and electronic units and will solve more effectively industrial problems. Nevertheless, in spite of difficulties for solving engineering problems this tendency is constant and demonstrates the progress of economics.

All industries are solved two primary problems, which are increase the productivity rate and manufacture high quality of products. All production systems designed for implementing technologies on manufacturing machines and systems and expected to get high output. Designed and computed correctly manufacturing machines and systems can solve these two problems. Industrial machineries computed on kinematics, dynamics, accuracy of machining, etc., and they are workable. Nevertheless, if industrial machines and systems do not computed on the productivity rate, they are not effective and useless. Hence, any productive machineries should be evaluated by two criterions, which are quantity and quality

of manufactured products. Quality of products is solved by theories of technological processes and practice. Quantity of products is solved by the productivity theory for industrial engineering. Latter one collected all achievements in analytical and practical experience in formulation the productivity rate for different manufacturing machines and systems with simple and complex designs.

The productivity is fundamental term in macro and microeconomics, which are considering two types of productivity. In macroeconomics, the term of productivity is the ratio of output to input, which can be dimensionless and represents the efficiency of the economic system according to the fundamental science. Microeconomics is considering the physical productivity as number of products fabricated per observation time (ASME). The productivity theory for industrial engineering considers the design of machineries by criterion of the physical productivity rate. This theory discovers engineering laws, regularities and reasonable links for creating new manufacturing machines and system. Productivity theory based on fundamental principles of theories of technology, machine design, reliability, efficiency, optimization of machining processes and structures of automated lines, managements, etc. Productivity theory for industrial engineering presents holistic mathematical models of productivity for machines and manufacturing systems, and demonstrates the links between physical productivity rate, reliability, technological and technical parameters, and the structure of machines and systems with complex designs. The productivity theory is universal and can be applied to any type of industries, i.e. manufacturing, textile, transport, chemical, etc. Nevertheless, final criterion for evaluation of industrial machineries remains the economic efficiency, which primary and weighty component is productivity rate of manufacturing machines and systems.

The known publications that present the mathematical models for productivity rate of machines and systems based on the partial and simple solutions that enable to derive 


\section{Robotics \& Automation Engineering Journal}

approximate equations for productivity rate. These approaches give simplified mathematical models for productivity rate of the manufacturing systems and results in calculation of approximated productivity rate can be far from real output of machineries. Manufacturers need correct and clear mathematical models that include main criterion for design and enable calculate with high accuracy the productivity rate of the machines and systems. This industrial demand is satisfied by the productivity theory that represents the analytical approach to productivity rate of the manufacturing machines and systems based on parameters of technological processes, reliability of mechanisms and units with different failure rates, and management systems. The mathematical models allow for the output of manufacturing machines and systems to be modelled with results that close to actual productivity. The accuracy of results in productivity rate depends on the accuracy of initial data of manufacturing processes only, which are indices of technology, reliability of mechanical, electrical, electronic units and machines and management. Any failure of such components leads to downtime of an expensive production machines and systems.

Contemporary manufacturing systems with complex designs have large structural variances with serial, parallel and mixed location of machines and workstations arranged according to the technological process. To predict the productivity rate of such complex and integrated production systems is crucial problem for engineering. Productivity theory for industrial engineering enables solving problems of optimization in technological and structural solutions. This theory covers the gap between a theoretical study of productivity for industrial machines and systems and practical achievements. Practitioners and manufacturers using productivity theory will have ability to solve optimally engineering problems of productivity for the manufacturing machines and complex systems. Conceptual principles of productivity theory for industrial machines and systemscontain the following components:

1. Technological processes and balancing are basis for structural designs of manufacturing machines and systems.

2. Mathematical models of productivity rate for a machine too land optimization of multi-tooling machining process by criterion of maximal productivity rate.

3. Mathematical models of productivity rate for manufacturing systems of serial, parallel and mixed structures with buffers for optimal structural solutions by criterion of maximal productivity rate.

4. Analysis of the work of industrial machines and systems in real manufacturing environments and discover the reason of productivity losses and solution to improve efficiency of machinery.

Productivity theory contains approaches of applying theoretical developments to engineering problems that is consistent with philosophy of engineering progress. The purpose of productivity theory is to guide the practitioners and manufacturers through the experience in an effective use of mathematical models for solving engineering problems for manufacturing processes.
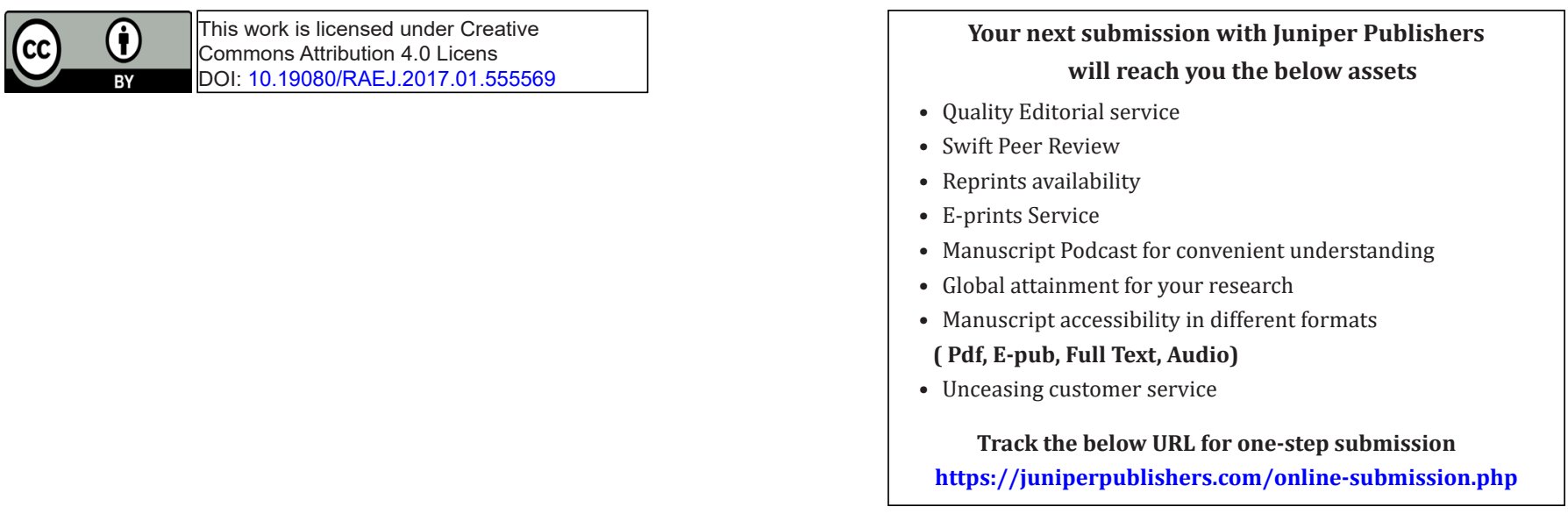